\title{
Aspects of the biology of Cryptocaryon irritans, and hyposalinity as a control measure in cultured gilt-head sea bream Sparus aurata
}

\author{
A. Colorni \\ Israel Oceanographic and Limnological Research Ltd., National Center for Mariculture, P.O.Box 1212, Eilat 88112, Israel
}

\begin{abstract}
The life cycle and halotolerance of Cryptocaryon irritans were studied. Trophonts completed their growth phase on the host in 3 to $7 \mathrm{~d}$. The reproductive process of the tomonts yielded tomites as early as 3 and as late as $28 \mathrm{~d}$. Tomite life span was 24 to $48 \mathrm{~h}$. Trophonts embedded in the fish skin withstood $18 \mathrm{~h}$ exposure of the host to fresh water. Tomonts withstood salinities ranging from 20 to $70 \%$ for $48 \mathrm{~h}$ without losing viability. Tomites were seen emerging only from tomonts kept in constant salinities ranging from 25 to $50 \%$. All tomonts degenerated when immersed in 0 to $10 \%$ for $3 \mathrm{~h}$. Eradication of the parasite based on these findings was achieved. Four consecutive treatments of $3 \mathrm{~h}$ each in $10 \%$ salinity $3 \mathrm{~d}$ apart destroyed all tomonts before tomites could excyst and were well tolerated by the fish. $C$. irritans life cycle was similarly interrupted by 4 consecutive transfers of fish into clean tanks at $3 \mathrm{~d}$ intervals. A certain degree of resistance to $C$. irritans invasion was observed in fish that had survived several infections.
\end{abstract}

\section{INTRODUCTION}

With the rapid development of intensive mariculture, the holotrich protozoan Cryptocaryon irritans Brown 1951, a parasite which once occurred only in marine aquaria (Brown 1951, de Graaf 1962, Nigrelli \& Ruggieri 1966, Wilkie \& Gordin 1969, Herwig 1978, Violetta 1980, Hignette 1981), has become in recent years an increasingly frequent pest in commercial maricultures (Sindermann 1977, Huff \& Burns 1981, Paperna 1983, G. Cuzon [Aquacop IFREMER/COP Tahiti] pers. comm.).

In the Red Sea, Cryptocaryon irritans infections were first observed in many species of coral fishes held in the aquaria of the Eilat Underwater Observatory (Colorni unpubl.). In winter 1983, C. irritans was diagnosed in moribund gilt-head sea bream Sparus aurata (L.) cultured in Eilat (Israel) at the National Center for Mariculture of the Israel Oceanographic and Limnological Research Ltd. (I.O.L.R.).

Cryptocaryon irritans invades the epithelium of the skin and gills of fish and affects the physiological function of these organs. Its life cycle, as described by several authors (Sikama 1961, Nigrelli \& Ruggieri 1966, Canella 1972), includes 3 main stages. The parasitic stage (trophont) lives embedded in the host's skin and feeds on tissue debris and body fluids; the mature trophont leaves the host, adheres to the substrate, encysts and begins to reproduce (tomont); after several divisions, the cyst ruptures, releasing the infective stage (tomites).

In the present study the biology of Cryptocaryon irritans was investigated with the objective of eradicating this parasite from the I.O.L.R. culture system. Considering the relatively high salinities of the Red Sea $(40 \pm 1 \%)$, the euryhalinity of Sparus aurata, and the fact that hyposalinity has already been suggested in the past as a promising measure of control (Herwig 1978, Cheung et al. 1979), particular emphasis was given to the tolerance of $C$. irritans to low salinities.

\section{MATERIALS AND METHODS}

Juveniles of several species of infected fish - Sparus aurata (L.), Pempheris vanicolensis (Cuvier \& Valenciennes), Diplodus noct (Cuvier \& Valenciennes), Mugil cephalus (L.), Oreochromis mossambicus (Peters), Abudefduf saxatilis (L.) - were kept in a small tank system (2 to $10 \mathrm{l}$ each) supplied with running seawater $\left(40 \pm 1 \% ; 24 \pm 1{ }^{\circ} \mathrm{C}\right)$. Juvenile $S$. aurata ( 2 to $3 \mathrm{~g}$ ) were periodically introduced and thus exposed to 
infection so that the parasite was available in all stages of development at any given time.

Groups of 2 or 3 infected fish were transferred into $600 \mathrm{ml}$ beakers. Mature trophonts dropped spontaneously from the fish and encysted overnight. The tomonts were dislodged gently the next day from the bottom of the beaker with a fine paint-brush and placed, singly or in small clusters, in separate wells of serological titration plates. Every 2 to $3 \mathrm{~d}$ they were rinsed with fresh sea water to prevent salinity increase by evaporation. Tomites were collected after the cysts ruptured. Immature trophonts were collected as they abandoned the host which had been previously sacrificed and left immersed in a Petri dish containing sea water.

Healthy, uninfected juvenile Sparus aurata were used to determine the duration of the trophont growing phase and of the tomont reproductive phase. The fish were exposed overnight to a large number of active tomites and were then transferred into separate $600 \mathrm{ml}$ beakers. Fish and beakers were checked daily under a dissecting stereoscope for presence of trophonts and tomonts, respectively. Collected tomonts were placed, singly or in small clusters, into wells of titration plates containing sea water (or test solutions) and observed daily for the presence of tomites. Viability of the emerging tomites was followed through several daily observations until motion ceased.

Tomont and tomite size was measured with a micrometer eyepiece. Tomont volume was extrapolated from tomont length and width using the equation $3 / 4 \pi$ $(\mathrm{L}+\mathrm{W} / 4)^{3}$ for calculating ovoid-sphere volume. Tomites were transferred from the wells to gridded plastic Petri dishes, killed with 2 or 3 drops of concentrated formalin, counted and measured.

Saline solutions ranging from 0 to $60 \%$ at $5 \%$ intervals were used to establish tolerance of Cryptocaryon irritans to salinity. Salinities below $40 \%$ were obtained by diluting sea water with unchlorinated tap water. Salinities above $40 \%$ were made using a hypersaline solution concentrated from sea water by evaporation. Salinities were confirmed with an American Optical ${ }^{\circledast}$ (Scientific Instrument Div., Box 123, Buffalo, NY 14240, USA) hand refractometer. Free swimming trophonts were immersed in the saline solutions and encystment was noted. Tomonts were incubated at $27^{\circ} \mathrm{C}$ for $3,6,12,24$ and $48 \mathrm{~h}$ before replacing the solutions with sea water.

Heavily infected juvenile Sparus aurata were used for in vivo experiments. Trophonts present in the tail and dorsal fin were used as reference since transparency of these parts allowed repeated microscope observations with no damage to the fish. The fish were acclimated to $20,15,10,5 \%$ and freshwater by diluting the sea water with tap water every hour by $5 \%$ and were left overnight in the final solution. The next day they were re-acclimated to sea water by reversing the procedure and observed for presence of live trophonts. The fish were kept 10 more days in $600 \mathrm{ml}$ beakers to collect the tomonts and check for their viability.

Once the duration of the Cryptocaryon irritans stage as trophont and the hyposaline tolerance limit of the tomont had been determined, 2 new series of experiments were conducted. In each, 10 fish were kept in a 11 beaker in which sea water was diluted with fresh water to $10 \%$ for $3 \mathrm{~h}$ every $3 \mathrm{rd}$ day for $10 \mathrm{~d}$. The bottom of the beaker was checked daily for presence of tomonts. A similar treatment was also adopted for a 4500 and a $14000 \mathrm{l}$ tank holding infected adult Sparus aurata.

\section{RESULTS}

Cryptocaryon irritans life cycle and halotolerance are summarized in Table 1.

Trophonts. Trophonts completed their growth phase on the fish 3 to $7 \mathrm{~d}$ after tomites invaded the fish, with a peak at Days 4 and 5.

Tomonts. Although the tomonts used in the experiments had spontaneously dropped as mature trophonts from the same fish within a limited period of time (16 to $18 \mathrm{~h})$ and had been incubated under identical conditions, tomites excysted asynchronously. Tomite excystment occurred as early as 3 but also as late as $28 \mathrm{~d}$ after the trophonts had dropped from the fish, with a peak time at Day $6 \pm 2$. No apparent relation was noted between tomont size and excystment time.

Tomites. The number of tomites produced by a tomont never exceeded 200 and was positively correlated to tomont volume. A power regression curve $(\mathrm{V}=$ $\left.706.654 \mathrm{n}^{0.781} ; \mathrm{n}=27\right)$ was successfully fitted $(\mathrm{R}=$ 0.851 ). The tomite life span was variable but was generally not less than 30 to $36 \mathrm{~h}$. In at least one case, some tomites were still seen moving weakly after $48 \mathrm{~h}$.

Sizes. Due to the plasticity of trophont shape, their size could best be estimated by the size of the tomonts. When trophonts had spontaneously dropped from the fish, tomonts measured $160 \times 150$ to $370 \times 310 \mu \mathrm{m}(241$ $\pm 22.04 \mathrm{SD} \times 214 \pm 30.30 \mathrm{SD}_{i} \mathrm{n}=138$ ). Trophonts that were prematurely forced to drop from the fish by the death of the host all encysted within $18 \mathrm{~h}$, including those less than $24 \mathrm{~h}$ old. However only tomonts of at least $60 \times 60 \mu \mathrm{m}$ were able to generate tomites. Below this size, tomonts invariably degenerated within 3 to $4 \mathrm{~d}$. Tomites measured 50 to $70 \times 20$ to $30 \mu \mathrm{m}$ (57 $\pm 6.8 \mathrm{SD} \times 25 \pm 2.9 \mathrm{SD} ; \mathrm{n}=50$ ).

Halotolerance. Trophonts that dropped from sacrificed fish were able to encyst in any salinity between 15 and $60 \%$. However, tomites were seen emerging only from tomonts incubated in salinities of between 
Table 1. Cryptocaryon irritans. Life cycle and halotolerance in its 3 stages

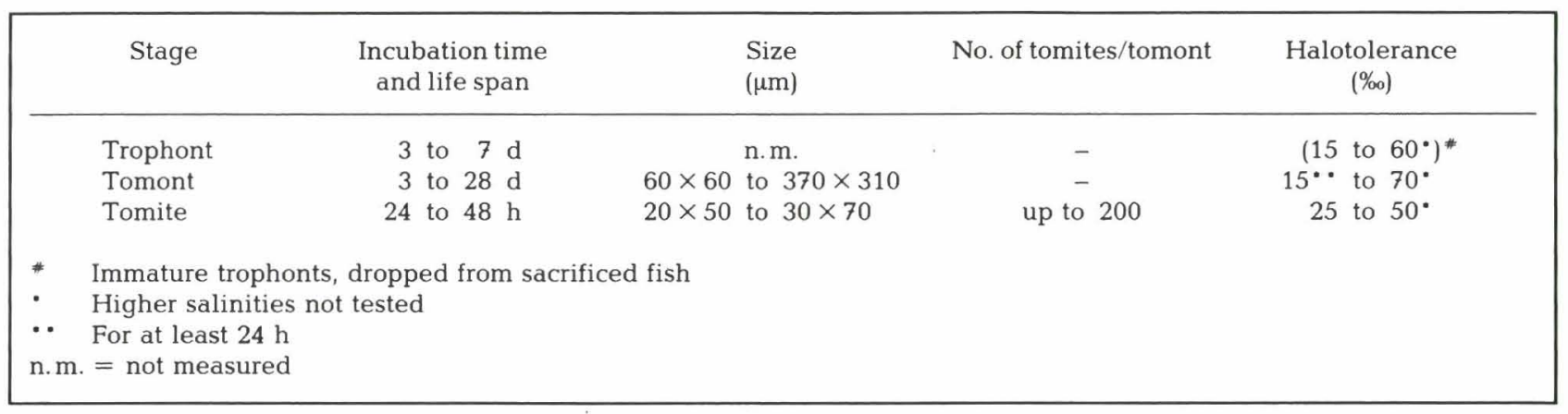

25 and $50 \%$. In identical conditions of temperature, tomites emerged as far as $17 \mathrm{~d}$ apart (40\%), $13 \mathrm{~d}$ apart (30 and $35 \%$ ) and $25 \mathrm{~d}$ apart (25\%). Tomonts kept in low salinity $(25 \%$ ) had in some cases a long incubation period ( 25 to $28 \mathrm{~d}$ ) and generated fewer live tomites. Tomonts could withstand exposure to both a gradual salinity increase of up to $70 \%$ (due to water evaporation over a 1 wk period), and a decrease of down to $20 \%$ by dilution for $48 \mathrm{~h}$. In neither case was viability lost, and excystment took place after the hyper- or hyposaline solution was replaced with sea water. Tomonts displayed varying degrees of resistance when immersed in salinities below $20 \%$. Tomites still emerged from tomonts kept in $15 \%$ for $24 \mathrm{~h}$. In 0 to $10 \%$ the tomont cysts often ruptured, releasing the endoplasm, although this rarely occurred when tomonts were clustered together. In any case all tomonts exposed to these salinities for $3 \mathrm{~h}$ eventually degenerated (Table 2).

Treatment. Most of the trophonts whose hosts had undergone hyposalinity treatment, including fresh water, for at least $18 \mathrm{~h}$, were still alive and occupied the same position in the host by the end of the experi-

Table 2. Tomont survival during exposure to low salinities

\begin{tabular}{|c|c|c|c|c|c|c|}
\hline \multirow{2}{*}{$\begin{array}{l}\text { Salinity } \\
(\%)\end{array}$} & \multicolumn{6}{|c|}{ Exposure time (h) } \\
\hline & 3 & 6 & 9 & 12 & 24 & 48 \\
\hline $40^{\circ}$ & + & + & + & + & + & + \\
\hline 20 & + & + & + & + & + & + \\
\hline 15 & + & + & + & + & + & - \\
\hline 10 & - & - & - & - & - & - \\
\hline 5 & - & - & - & - & - & - \\
\hline $0^{\cdots}$ & - & - & - & - & - & - \\
\hline \multicolumn{7}{|c|}{$\begin{array}{l}\text { + No apparent damage caused to the cyst. Active tomites } \\
\text { later produced } \\
\text { - Division process interrupted; endoplasm degeneration. } \\
\text { No tomites produced } \\
\text { - Sea water (control) } \\
\text { - Unchlorinated tap water }\end{array}$} \\
\hline
\end{tabular}

ment, following re-adaptation to sea water. They later dropped from the fish, encysted, and the tomonts produced tomites.

In the beakers in which salinity was reduced for $3 \mathrm{~h}$ to $10 \% 4$ times at $3 \mathrm{~d}$ intervals, tomonts were destroyed after each treatment and the fish were free from infection in 5 to $8 \mathrm{~d}$. Similar results were obtained when this procedure was applied to the 4500 and the $14000 \mathrm{l}$ tanks.

Total eradication of Cryptocaryon irritans was also achieved within $10 \mathrm{~d}$ by switching fish between 2 tanks. Four switches at $3 \mathrm{~d}$ intervals were needed, the tanks being dried and cleaned between uses.

Fish susceptibility. Different species of fish showed different susceptibility to Cryptocaryon irritans infections. While Pempheris vanicolensis and Sparus aurata juveniles were readily infected and usually died within 1 or 2 wk, Mugil cephalus, Oreochromis mossambicus and Abudefduf saxatilis, which were kept in the same infected tank, survived several waves of tomite attacks after which they apparently acquired immunity, sustaining little or no infection for several months. $S$. aurata larvae as young as $3 \mathrm{wk}$ could be infected.

\section{DISCUSSION}

The host epidermis and the thick layer of mucus secreted in response to the irritating presence of the trophonts form a barrier impervious to osmotic shock. Huff \& Burns (1981) suggested hypersalinity as a method to remove excessive mucus and thus expose the trophonts to subsequent chemical treatment. However, although neither the resistance of Sparus aurata nor the infectivity of the tomites in salinities above $40 \%$ was tested, it is considered that hypersalinity is likely more detrimental to the host than to the parasite. Herwig (1978) and Cheung et al. (1979) suggested hyposalinity as an alternative way to reach the trophonts and upset their osmotic balance. However, in the present study, embedded trophonts did not seem to 
be affected by a freshwater treatment of the host for as long as $18 \mathrm{~h}$.

The prolonged division process which Cryptocaryon irritans tomonts can undergo makes treatment even more problematic. The reason for lack of synchrony in excystment among tomonts of the same age, kept under identical incubation conditions, is still unclear. Apparently temperature and salinity are not the only factors influencing the reproductive process. Tomite number in large tomonts suggests a maximum of 7 or 8 possible divisions, but the results obtained do not show any apparent relation between tomont size and excystment time. If the tomites were to emerge simultaneously during a short-term adverse condition, the parasite could be easily destroyed. In fact such asynchrony in tomont sporulation is so advantageous to C. irritans that the phenomenon may be interpreted as a strategy for survival.

Although different species of fish showed different susceptibility to Cryptocaryon irritans infections, this parasite is not very fastidious in its host selection (Nigrelli \& Ruggieri 1966, Wilkie \& Gordin 1969, D. Fridman [Eilat Underwater Observatory] pers. comm.). Furthermore, small size and early development stage of the host are not a limiting factor for the parasite, as the infection of Sparus aurata larvae demonstrated. These facts indicate that $C$. irritans poses a threat to virtually any culture of marine fish.

The efficacy of the hyposalinity treatment lies in the fact that, when administered at the concentration, duration and frequency described in the present work, the osmotic shock destroys all the tomonts before they can complete their division process. The life cycle of Cryptocaryon irritans can also be interrupted by transfers of the fish carried out with the same frequency. However, handling fish that are already weakened by the disease may not always be an advisable method. The hyposalinity treatment was well tolerated by Sparus aurata, which can withstand even longer exposures to lower salinities (Chervinski 1979, Colorni unpubl.), but less euryhaline species may also be able to tolerate this therapy without excessive stress.

Acknowledgements. I am indebted to Prof. I. Paperna of the $\mathrm{H}$. Steinitz Marine Biology Laboratory of the Hebrew University of Jerusalem (Eilat) and Mr J. K. Staarman of the Fisheries Science Dept., Agricultural University of Wageningen (The Netherlands), whose studies of Cryptocaryon irritans pathology were the starting point for the present work. I am thankful to Mr Ezra Shmuel and Mr Davvid Flax of the I.O.L.R. for their technical assistance. The critical reading of the manuscript by Prof. Paperna and by Dr. A. Diamant of the Inter-University Institute of Eilat was invaluable and is gratefully acknowledged.

\section{LITERATURE CITED}

Brown, E. M. (1951). A new parasitic protozoan the causal organism of a white spot disease in marine fish - Cryptocaryon irritans gen. and sp. n. Agenda and Abstracts of the Scientific Meeting of the Zoological Society of London, 1950, 11: 1-2

Canella, M. F. (1972). Ce qu'on ne connaît pas sur un holotriche ectoparasite des poissons marins, découvert par le Dr. Sikama et appelé Cryptocaryon irritans par Miss Brown. Contributions à la connaissance des Ciliés, VII. Annali dell'Università di Ferrara, Italy, Nuova Serie, Sez. III, Biologia Animale III (9): 107-132

Chervinski, J. (1979). Preliminary experiments on the adaptability of juvenile European sea bass (Dicentrarchus labrax [L]) and gilthead sea bream (Sparus aurata [L]) to brackish water. Bamidgeh 31 (1): 14-17

Cheung, P. J., Nigrelli, R. F., Ruggieri, G. D. (1979). Studies on cryptocaryoniasis in marine fish: effect of temperature and salinity on the reproductive cycle of Cryptocaryon irritans Brown, 1951. J. Fish Dis. 2: 93-97

Graaf, F. de (1962). A new parasite causing epidemic infection in captive Coralfishes. Bull. Inst. océanogr. Monaco, No. spécial 1-A: 1er Congrès International d'Aquariologie, Monaco, 1960. Communications, Vol. A: 93-96

Herwig, N. (1978). Notes on the treatment of Cryptocaryon. Drum and Croaker 18 (1): 6-12

Hignette, M. (1981). Utilization de sels métalliques comme traitement antiparasitaire en aquariologie marine. Vie marine 3: 133-138

Huff, J. A., Burns, C. D. (1981). Hypersaline and chemical control of Cryptocaryon irritans in red snapper, Lutjanus campechanus, monoculture. Aquaculture 22: 181-184

Nigrelli, R. F., Ruggieri, G. D. (1966). Enzootics in the New York Aquarium caused by Cryptocaryon irritans Brown, 1951 (=Ichthyophthirius marinus Sikama, 1961), a histophagous ciliate in the skin, eyes and gills of marine fishes. Zoologica, New York 51 (9): 97-102 (+ 7 unpaged plates)

Paperna, I. (1983). Review of diseases of cultured warm-water marine fish. Rapp. P.-v. Réun. Cons. int. Explor. Mer 182: $44-48$

Sikama, Y. (1961). On a new species of Ichthyophthirius found in marine fishes. Sciences Reports of the Yokosuka City Museum 6: 66-70

Sindermann, C. J. (ed.) (1977). Disease diagnosis and control in North American marine aquaculture. Developments in aquaculture and fisheries science 6, Elsevier Scientific Publishing Co., New York

Violetta, G. (1980). Disease prevention and control, a review of two epizootic marine protozoans: Oodinium ocellatum and Cryptocaryon irritans. Freshwat. mar. Aquar. $3(6)$ : $52-53,70-72$

Wilkie, D. W., Gordin, H. (1969). Outbreak of cryptocaryoniasis in marine aquaria at Scripps Institute of Oceanography. Calif. Fish Game 55 (3): 227-236 